\title{
Introgression of rpg 4/Rpg5 Into Barley Germplasm Provides Insights Into the Genetics of Resistance to Puccinia graminis f. sp. tritici Race TTKSK and Resources for Developing Resistant Cultivars
}

\author{
Javier Hernandez, ${ }^{1}$ Brian J. Steffenson, ${ }^{2}$ Tanya Filichkin, ${ }^{1}$ Scott P. Fisk, ${ }^{1}$ Laura Helgerson, ${ }^{1}$ Brigid Meints, ${ }^{1}$ \\ Kelly J. Vining, ${ }^{3}$ David Marshall, ${ }^{4}$ Alicia del Blanco, ${ }^{5}$ Xianming Chen, ${ }^{6}$ and Patrick M. Hayes ${ }^{1, \dagger}$ \\ ${ }^{1}$ Department of Crop and Soil Science, Oregon State University, Corvallis, OR 97331 \\ 2 Department of Plant Pathology, University of Minnesota, St. Paul, MN 55108 \\ ${ }^{3}$ Department of Horticulture, Oregon State University, Corvallis, OR 97331 \\ ${ }^{4}$ U.S. Department of Agriculture Agricultural Research Service, Raleigh, NC 27695 \\ 5 Department of Plant Sciences, University of California, Davis, CA 95616 \\ ${ }^{6}$ U.S. Department of Agriculture Agricultural Research Service Wheat Health, Genetics, and Quality Research Unit and Department of Plant \\ Pathology, Washington State University, Pullman, WA 99164-6430 \\ Accepted for publication 29 January 2019.
}

\begin{abstract}
Stem rust (incited by Puccinia graminis f. sp. tritici) is a devastating disease of wheat and barley in many production areas. The widely virulent African $P$. graminis f. sp. tritici race TTKSK is of particular concern, because most cultivars are susceptible. To prepare for the possible arrival of race TTKSK in North America, we crossed a range of barley germplasm - representing different growth habits and end useswith donors of stem rust resistance genes Rpgl and rpg4/Rpg5. The former confers resistance to prevalent races of $P$. graminis f. sp. tritici in North America, and the latter confers resistance to TTKSK and other closely related races from Africa. We produced doubled haploids from these crosses and determined their allele type at the Rpg loci and haplotype at 7,864 single-nucleotide polymorphism loci. The doubled haploids were phenotyped for TTKSK resistance at the seedling stage.

Integration of genotype and phenotype data revealed that (i) Rpg1 was not associated with TTKSK resistance, (ii) rpg4/Rpg5 was necessary but was not sufficient for resistance, and (iii) specific haplotypes at two quantitative trait loci were required for $r p g 4 / R p g 5$ to confer resistance to TTKSK. To confirm whether lines found resistant to TTKSK at the seedling resistance were also resistant at the adult plant stage, a subset of doubled haploids was evaluated in Kenya. Additionally, adult plant resistance to leaf rust and stripe rust (incited by Puccinia hordei and Puccinia striiformis f. sp. hordei, respectively) was also assessed on the doubled haploids in field trials at three locations in the United States over a 2-year period. Doubled haploids were identified with adult plant resistance to all three rusts, and this germplasm is available to the research and breeding communities.
\end{abstract}

Barley (Hordeum vulgare L.) is the fourth most important cereal crop in the world (FAOSTAT 2014), and $>800,000$ ha were produced in the United States in 2017 (USDA-NASS 2018). The total economic impact of the crop is estimated at $\sim \$ 1.2$ billion/year owing to the critical importance of barley in the manufacturing of malt and beer (USDA-NASS 2012). Barley as a human food also has tremendous potential to assist in addressing health challenges, including heart diseases, type 1 diabetes, and obesity (Meints et al. 2016).

However, abiotic and biotic stresses are continual threats to barley production and quality. A particularly serious disease threat is stem rust incited by the basidiomycetous fungi Puccinia graminis f. sp. tritici Erikss. \& E. Henn. (wheat stem rust pathogen) and Puccinia graminis f. sp. secalis Erikss. \& E. Henn. (rye stem rust pathogen) (Roelfs 1985; Steffenson 1992). Since 1942, barley

${ }^{\dagger}$ Corresponding author: P. M. Hayes; patrick.m.hayes@oregonstate.edu

Funding: This research was supported by U.S. Department of Agriculture, Agricultural Research Service Non-Assistance Cooperative Agreements "Developing Northwest-Adapted Barleys With Resistance to Stem Rust" award 582072-5-037 and "Screening Barley Germplasm to Discover Genes Conferring Durable Resistance to Barley Stripe Rust" award 58-2050-6-005.

*The $\boldsymbol{e}$-Xtra logo stands for "electronic extra" and indicates that three supplementary figures and six supplementary tables are published online.

The author(s) declare no conflict of interest.

(C) 2019 The American Phytopathological Society losses owing to wheat stem rust in the United States have been largely controlled through deployment of the resistant gene Rpg1 (Roelfs 1985; Steffenson 1992). However, a new widely virulent race of $P$. graminis f. sp. tritici, designated TTKSK (isolate synonym Ug99), was described from Uganda in 1999 (Pretorius et al. 2000). TTKSK has the potential to be a major threat to wheat and barley production in the United States and around the world. In wheat, TTKSK is virulent on the widely deployed resistance gene $\mathrm{Sr} 31$ as well as other $\mathrm{Sr}$ genes (Jin and Singh 2006; Pretorius et al. 2000 ), and it could negatively impact $>90 \%$ of the world's wheat production (Singh et al. 2006, 2008). TTKSK is also widely virulent on barley, including varieties and germplasm carrying Rpgl (Steffenson and Jin 2006; Steffenson et al. 2013). Steffenson et al. (2017) found that $>95 \%$ of the barley germplasm surveyed is susceptible to this race. Currently, at least one of the races within the Ug99 lineage has been found throughout Africa (Uganda, Kenya, Ethiopia, Eritrea, Egypt, South Africa, Tanzania, Zimbabwe, and Mozambique) and in the Middle East (Yemen and Iran) (Mukoyi et al. 2011; Nazari et al. 2009; Pretorius et al. 2000, 2010, 2012; Wolday et al. 2011). Deployment of resistant varieties is the most effective, economical, and environmentally appropriate approach to managing this disease (Pilet-Nayel et al. 2017; Steffenson and Smith 2006).

Eight genes/loci conferring resistance to different races of $P$. graminis f. sp. tritici in wild and cultivated barley have been described (Case et al. 2018b; Mamo et al. 2015; Zhou et al. 2014). The most effective and well-characterized source of all-stage resistance to race TTKSK is the $r p g 4 / R p g 5$ complex first reported in 
barley accession Q21861 (PI 584766) and mapped to chromosome 5HL (Steffenson et al. 2009). Based on high-resolution mapping, rpg4/Rpg5 is known to be a complex locus consisting of multiple genes in physical proximity (Wang et al. 2013). Briefly, this complex locus is further subdivided into RMRL1 and RMRL2. Three genes have been characterized at RMRL1: Rpg5 (encoding an NBS-LRR protein kinase), HvRgal (encoding an NBS-LRR domain protein), and $H v A d f 3$ (an actin depolymerizing factor-like gene). The genes within RMRL2 have yet to be fully characterized. Although rare recombinants have been found, the rpg4/Rpg5 locus can be viewed tactically as the single major gene protecting the barley crop from virulent races, like TTKSK and isolates of P. graminis f. sp. secalis. Strategically, a more durable defense could be built on multiple diverse sources of resistance. Gene stacking can provide durability and increased levels of resistance, such as was shown for barley stripe rust (Castro et al. 2003a, b; Edae et al. 2018)

Despite extensive characterization of the wild and cultivated Hordeum germplasm pools, sources of resistance to race TTKSK other than rpg4/Rpg5 are rare (Case et al. 2018b; Sallam et al. 2017; Steffenson et al. 2017; Zhou et al. 2014). Development of TTKSKresistant barley varieties can be achieved by introgressing rpg4/ Rpg5 into adapted germplasm followed by the pyramiding of any newly discovered resistance alleles as they are discovered. Pyramiding resistance into adapted germplasm with acceptable agronomic characteristics can be facilitated by marker-assisted selection (MAS) (Arunakumari et al. 2016; Castro et al. 2003a; Friedt and Ordon 2007; Mohan et al. 1997; Richardson et al. 2006). The success of marker-assisted pyramiding, however, can vary depending on the genetic background: introgressed alleles may not always have the anticipated effects on levels of resistance (Bilgic et al. 2005; Steffenson and Smith 2006). Therefore, the performance of MAS introgression lines must be validated by field or greenhouse experiments. In the case of TTKSK, phenotyping is challenging, because the race is not yet present in the United States. Therefore, phenotyping can only be conducted in a Biosafety Level3 (BSL-3) Containment Facility, where space and resource considerations dictate seedling assessments of large germplasm arrays. Assessing resistance levels in adult plants relies on international nurseries where race TTKSK occurs. A key resource for U.S. breeders is the U.S. Department of Agriculture Agricultural Research Service (USDA-ARS) Kenya Stem Rust Nursery, although the number of barley varieties and elite germplasm accessions that can be assessed in this trial is limited.

A goal of the Oregon State University Barley Project is to develop barley germplasm representing different potential end uses with resistance to multiple diseases, including the African stem races typified by TTKSK. The objectives of this research were to (i) introgress $r p g 4 / R p g 5$ into diverse genetic backgrounds, (ii) assess the effectiveness of rpg4/Rpg5 in these different genetic backgrounds, (iii) determine if other genes/quantitative trait loci (QTLs) conferring resistance to TTKSK could be identified, and (4) assess the resistance of TTKSK-resistant germplasm to stripe rust (incited by Puccinia striiformis f. sp. hordei) and leaf rust (incited by Puccinia hordei G.H. Otth).

\section{MATERIALS AND METHODS}

Plant material. Crosses between parental accessions, hereafter referred to as parents, reported to be resistant or susceptible to TTKSK were made in 2014 (Table 1). The resistant parents MC0181-11, SH98076, SB97197, TR02272, and MC0181-31 were provided by B. J. Steffenson at the University of Minnesota based on their seedling resistance to race TTKSK. These resistant donors were developed by B. Rossnagel, A. Beattie (Crops Development Centre, University of Saskatchewan, Saskatoon, Canada), and B. Legge (Agriculture and Agri-Food Canada, Brandon, Manitoba, Canada). All resistance donors have Q21861, a source of rpg4/ Rpg5, in their pedigree. In brief, MC0181-11 and MC0181-31 were selected from the cross of SH00752 × 9-1, where Q21861 was a parent of 9-1. Doubled haploid progeny from the cross of Q21861 $\times$ SM89010 (Steffenson et al. 1995) were used as parents in developing SH98076 and SB97197. TR02272 is a backcrossderived line with Q21861 as the donor parent and AC Metcalfe as the recurrent parent. The susceptible parents used in this study were selected based on different characteristics, such as growth habit, hull type, spike type, and malting quality profile. Full Pint, 04_028_36, and Violetta are varieties or elite lines with covered

TABLE 1. Parental accession reactions to seedling inoculation with Puccinia graminis f. sp. tritici race TTKSK ${ }^{\mathrm{a}}$

\begin{tabular}{|c|c|c|c|c|}
\hline Line & Origin & IT-M (GR) ${ }^{\mathrm{b}}$ & $\mathrm{CI}^{\mathrm{c}}$ & Genotype $^{\mathrm{d}}$ \\
\hline MC0181-11 & $\begin{array}{l}\text { Saskatchewan, Canada (University of } \\
\text { Saskatchewan) }\end{array}$ & $210 ;(\mathrm{R})$ & 2.5 & Rpg1, rpg4/Rpg5 \\
\hline MC0181-31 & $\begin{array}{l}\text { Saskatchewan, Canada (University of } \\
\text { Saskatchewan) }\end{array}$ & $3-(\mathrm{MS})$ & 3.3 & Rpg1, rpg4/Rpg5 \\
\hline SH98076 & $\begin{array}{l}\text { Saskatchewan, Canada (University of } \\
\text { Saskatchewan) }\end{array}$ & $0 ;(\mathrm{R})$ & 0.5 & Rpg1, rpg4/Rpg5 \\
\hline SB97197 & $\begin{array}{l}\text { Saskatchewan, Canada (University of } \\
\text { Saskatchewan) }\end{array}$ & $23-(\mathrm{MR})$ & 3.2 & Rpg1, rpg4/Rpg5 \\
\hline TR02272 & Manitoba, Canada (Agri-Food Canada) & 1 to $20 ;(\mathrm{R})$ & 1.8 & Rpg1, rpg4/Rpg5 \\
\hline Full Pint & Oregon, U.S.A. (Oregon State University) & $2 ; 3-(\mathrm{S})$ & 3.4 & $\longrightarrow$, \\
\hline 04_028_36 & $\begin{array}{l}\text { Germany (Ackerman Saatzucht } \\
\text { GmbH \& Co.) }\end{array}$ & $33+(S)$ & 4.1 & rpg1, Rpg4/rpg5 \\
\hline Violetta & $\begin{array}{l}\text { Germany (Saatzucht Josef Breun } \\
\text { GmbH \& Co.) }\end{array}$ & $3(\mathrm{~S})$ & 4.0 & rpg1, Rpg4/rpg5 \\
\hline 10.0691 & Oregon, U.S.A. (Oregon State University) & $3(\mathrm{~S})$ & 4.0 & rpg1, Rpg4/rpg5 \\
\hline 10.1151 & Oregon, U.S.A. (Oregon State University) & $3(\mathrm{~S})$ & 4.0 & $\longrightarrow$, Rpg4/rpg5 \\
\hline Karma & Tibet (USDA NSGGC PI 60205) & $23(\mathrm{~S})$ & 3.7 & $\longrightarrow$, Rpg4/rpg5 \\
\hline Oscar & $\begin{array}{l}\text { Washington, U.S.A. (Washington State } \\
\text { University) }\end{array}$ & $3-(\mathrm{S})$ & 3.5 & $\longrightarrow, \operatorname{rpg} 4 / \operatorname{Rpg} 5^{\mathrm{f}}$ \\
\hline Tibet 37 & Tibet (James Hutton Institute, Scotland) & $23(\mathrm{~S})$ & 3.7 & $\longrightarrow, \mathrm{C}^{\mathrm{e}}$ \\
\hline
\end{tabular}

a GR, general reaction; MR, moderately resistant; MS, moderately susceptible; R, resistant; S, susceptible.

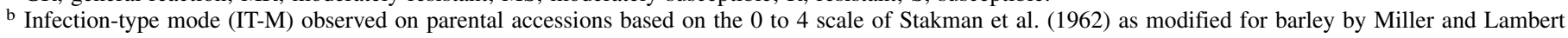
(1955).

c Coefficient of infection (CI) mean from two replicates calculated as described by Zhou et al. (2014).

d Rpg1 and rpg4/Rpg5 are the resistant genotypes, and rpg1 and Rpg4/rpg5 are the susceptible genotypes.

e No polymerase chain reaction amplification product.

f Rpg5+ allele amplicon, premature stop codon. 
caryopses (hulled) and feature target traits, including resistance to stripe rust, leaf rust, powdery mildew (incited by Blumeria graminis f. sp. hordei), and malting quality; 10.0691, 10.1151, Karma, Oscar, and Tibet 37 are naked caryopsis types (hulless; nud/nud) (Taketa et al. 2004) of particular interest for use as human food. One hundred nineteen doubled haploids were produced at Oregon State University from the $F_{1}$ of TTKSK-resistant $\times$ TTKSK-susceptible crosses (Table 2) using the anther culture protocol described by Cistué et al. (2011). These doubled haploids constitute the "TTKSK Cycle I population," hereafter referred to as the Cycle I population. This designation is based on the continuing development of new TTKSK-resistant doubled haploids populations. For example, Cycle II phenotyping, genotyping, and analyses are in progress (https://barleyworld.org/ug99; accessed August 2018), and Cycle III germplasm development is in progress. The Cycle I population and parents were genotyped with the Infinium iSelect 9K Genotyping BeadChip (Illumina, Inc., San Diego, CA) (Comadran et al. 2012) and used to perform a genome-wide association study (GWAS). Progeny $(n=117)$ were genotyped with allele-specific primers for the Rpgl and Rpg5 stem rust resistance genes at Functional Bioscience Inc. (Madison, WI) following the procedures described below. Two doubled haploids (of the original 119) were dropped, because they did not produce sufficient seed. For analyses of segregation ratios, 110 doubled haploids were used for the reasons described below.

TTKSK resistance phenotyping at the seedling stage. In 2015, the parents, Cycle I population, and controls were phenotyped at the seedling stage for response to $P$. graminis $\mathrm{f}$. sp. tritici race TTKSK in the BSL-3 Containment Facility at the University of Minnesota in St. Paul. The experiment was designed as a randomized complete block with two replications and replicated controls. Plant growth conditions and inoculation procedures were as described in Steffenson et al. (2017). Briefly, five seeds of each barley genotype were planted per pot. Plants were grown in a greenhouse at 20 to $22^{\circ} \mathrm{C}$ with supplemental lighting provided by $400-\mathrm{W}$ sodium vapor lamps for a $14-\mathrm{h} / 24-\mathrm{h}$ light/dark period. The irradiance at canopy level was $300 \mu \mathrm{mol} \mathrm{m} \mathrm{m}^{-2} \mathrm{~s}^{-1}$. Isolate 04KEN156/04 was used as the source of $P$. graminis f. sp. tritici race TTKSK. The inoculum was previously increased on susceptible wheat host McNair 701 (CI15288), collected, desiccated, and stored in tubes at $-80^{\circ} \mathrm{C}$

TABLE 2. Number of TTKSK Cycle I doubled haploids (DHs) produced from each cross $^{\mathrm{a}}$

\begin{tabular}{|c|c|c|c|}
\hline Pedigree $^{b}$ & Number of DHs & Resistant & Susceptible \\
\hline MC0181-11 × 10.1151 & 1 & 0 & 1 \\
\hline MC0181-11 × Tibet 37 & 2 & 1 & 1 \\
\hline MC0181-11 × Full Pint & 6 & 3 & 3 \\
\hline $10.0691 \times \mathrm{MC} 0181-11$ & 3 & 0 & 3 \\
\hline 04_028_36 × MC0181-11 & 1 & 0 & 1 \\
\hline MC0181-11 × & 13 & 4 & 9 \\
\hline MC0181-31 × Oscar & 5 & 0 & 5 \\
\hline Violetta $\times$ MC0181-31 & 3 & 0 & 3 \\
\hline MC0181-31 $\times$ & 8 & 0 & 8 \\
\hline SH98076 × 10.1151 & 34 & 8 & 26 \\
\hline SH98076 × Karma & 1 & 1 & 0 \\
\hline SH98076 $\times$ Full Pint & 20 & 5 & 15 \\
\hline Violetta × SH98076 & 1 & 1 & 0 \\
\hline SH98076 $\times$ & 56 & 15 & 41 \\
\hline SB97197 × 04_028_36 & 29 & 3 & 26 \\
\hline SB97197 × Violetta & 11 & 0 & 11 \\
\hline SB97197 × & 40 & 3 & 37 \\
\hline Violetta $\times$ TR02272 & 2 & 0 & 2 \\
\hline TR02272 × & 2 & 0 & 2 \\
\hline Total DH lines & $119^{c}$ & 22 & 97 \\
\hline
\end{tabular}

a Reaction classification was recorded based on the threshold coefficient of infection of $\leq 2.8$

b Total numbers of DH progeny for each donor parent are given in bold. Progeny excluded from genetic analyses are given in italics.

${ }^{c}$ Lines used for genome-wide association study. until needed. A rust spore suspension $(0.017 \mathrm{mg}$ of urediniospores per $1 \mathrm{ml}$ of oil) was applied to seedlings with fully expanded primary leaves at a rate of $0.149 \mathrm{mg}$ of rust per plant. After inoculation, plants were transferred to a dark mist chamber, where the relative humidity was maintained near $100 \%$. Twelve days after inoculation, stem rust infection types (ITs) were assessed on the first leaves of plants based on the 0 to 4 scale developed for wheat (Stakman et al. 1962) as modified for barley by Miller and Lambert (1955). All ITs observed on each doubled haploid, parent, and control were recorded as previously described by Sun and Steffenson (2005). When two or three ITs were observed on an accession, IT scores were recorded in order of prevalence. For GWAS, IT values were transformed to numerical values as described by Zhou et al. (2014), who showed that the numeric transformation reflects biological and epidemiological differences in the host-parasite interactions. The coefficient of infection (CI) was then calculated as described by Zhou et al. (2014). For $\chi^{2}$ tests, mean CI values were calculated from two replicates. A threshold of 2.8 was used to classify germplasm as resistant (mean $\mathrm{CI} \leq 2.8$ ) or susceptible (mean $\mathrm{CI}>2.8$ ) based on histogram distribution of CIs and previous reports (Sallam et al. 2017).

TTKSK resistance phenotyping at the adult stage. Selected entries from the Cycle I population were evaluated for stem rust resistance at the adult stage in trials conducted at Njoro, Kenya in 2016 and 2017. Resistant entries were selected only on controlled environment phenotypic data as the genotyping was in progress. Field trials were a collaboration between USDA-ARS, the International Maize and Wheat Improvement Center (CIMMYT), and the Kenya Agricultural \& Livestock Research Organization. In each year, all of the lines were vernalized for 6 weeks at $4^{\circ} \mathrm{C}$ and then transplanted to the field in hill plots spaced $\sim 30 \mathrm{~cm}$ apart. A mixture of stem rust-susceptible local spring wheat cultivars was planted in a continuous strip directly adjacent to each hill plot to provide adequate rust inoculum. No hill plot was $>10 \mathrm{~cm}$ away from the spreader. Plants in the spreaders were inoculated at booting and heading growth stages by injecting urediniospores directly into stems to promote infection and spore production. The inoculum in both years included races TTKSK, TTKST, and TTKTK. Stem rust severity was assessed between grain milk and dough development (Zadoks GS71-83). Disease severity was recorded as the percentage of stem and leaf sheath tissue infected with stem rust using the modified Cobb scale (0 to 100\%) (Peterson et al. 1948).

Phenotyping for resistance to other rusts. The 117 doubled haploids used for allele identification at the Rpg 1 and Rpg 5 loci (see below) were phenotyped for resistance to stripe rust and leaf rust. Data were obtained from multiple field trials conducted in Davis, California; Corvallis, Oregon; and Mount Vernon, Washington during the 2016 and 2017 seasons. All locations consistently have natural inoculum and favorable conditions for the development of these diseases. The experiment was designed as a randomized complete block with two replications at each location. Field ratings were taken between heading and before senescence. Disease severity was recorded as a percentage of the leaf area infected with stripe and leaf rust (including necrotic and chlorotic areas) on a per plot basis. An $80 \%$ reduction in severity compared with the susceptible check was used as the threshold to separate susceptible versus resistant lines. Phenotypic information is available online at https://barleyworld.org/barley-stripe-rust-bsr (accessed August 2018).

Single-nucleotide polymorphism genotyping. Leaf tissue from the Cycle I population and parents was collected at the seedling stage from greenhouse-grown plants at Oregon State University (Corvallis, OR) and sent to the USDA-ARS Regional Small Grains Genotyping Laboratory at Fargo, North Dakota for DNA extraction and genotyping with the 7,864 single-nucleotide polymorphism (SNP) markers represented on the Infinium iSelect 9K Genotyping BeadChip (Illumina, Inc., San Diego, CA) (Comadran et al. 2012). After filtering for minor allele frequency 
$(<0.05)$ and missing data $(>10 \%)$, 5,470 SNPs were used for subsequent analyses. To define SNP positions in the genome, the consensus map from Muñoz-Amatriaín et al. (2014) and the barley reference genome from Mascher et al. (2017) were used.

Allele-specific genotyping at $\operatorname{Rpg} 1$ and $\boldsymbol{R p g} 5$. DNA was extracted from 117 Cycle I lines and parents at the Center for Genome Research and Biocomputing at Oregon State University (Corvallis, OR). Genotyping and sequencing were performed at Functional Bioscience Inc. (Madison, WI) as described by Steffenson et al. (2017). Briefly, primers amplifying the serine threonine protein kinase domain (Rpg5+) or the protein phosphatase 2C domain (rpg5-) were used to discriminate the functional Rpg5 allele from the nonfunctional rpg5 allele. Following the nomenclature of Mamo et al. (2015), the primer combinations were LRK-F1/LRK-R1 and RpgQ-F6/PP2C-R2. Doubled haploids and parents showing a polymerase chain reaction product from primers LRK-F1/LRK-R1 were sequenced to assay for the infrequent allele that gives a false positive as a result of a single $\mathrm{C}$ insertion that causes a truncated nonfunctional RPG protein. The Rpgl assay was conducted as described by Eckstein et al. (2003) and later modified by Derevnina et al. (2014).

Association mapping. Phenotypic distributions for seedling reaction to race TTKSK were visualized using histograms. Phenotypic means were then transformed using $\log _{10}$, square, and square root transformations. The Shapiro-Wilk test was performed in $\mathrm{R}$ (R Development Core Team 2015) to compare normality of the transformed and untransformed CI means. To detect associations between SNP markers and stem rust phenotypes at the seedling stage, GWAS was performed in TASSEL (version 5.2.40) (Bradbury et al. 2007) using a mixed linear model $(Q+K)$ (Yu et al. 2006). Using principal component (PC) analysis, the first three PCs were used to construct the $Q$ matrix. These PCs were selected based on screening the eigenvalues and corresponding PCs (Price et al. 2006). The $K$ matrix was used to account for genetic relatedness within individuals. Both components were calculated using TASSEL (version 5.2.40). The significance of the marker-trait associations was based on false discovery rates (FDRs) of 5 and $10 \%$ as described by Benjamini and Hochberg (1995). Subsequently, the FDR (5\%) was calculated using only selected SNPs mapping to regions of chromosomes $4 \mathrm{H}, 5 \mathrm{H}$, and $7 \mathrm{H}$, where nearsignificant effects were detected using all markers and where major genes and/or QTLs have been reported for resistance to leaf rust, stem rust, and/or stripe rust. The targeting of specific regions using a subset of SNPs was based on the rationale and examples provided by Lipka et al. (2013, 2015). To further investigate the significance of marker-CI main effects and interactions, we followed the example of Castro et al. (2003b) in which the most significant SNPs at each QTL were used in an analysis of variance (ANOVA) as independent variables with two levels each, where each level corresponds to an allele. The sums of squares and significance for each QTL and their interactions were estimated. These analyses were performed in R (R Development Core Team 2015), where $F$ statistics for the sources of variation were estimated using the type III sums of squares.

Data availability. All phenotype and genotype data are available at https://barleyworld.org/ug99.

\section{RESULTS}

Phenotypic analysis of seedling resistance to TTKSK. Inoculation of germplasm with race TTKSK at the seedling stage resulted in clearly recognizable differences, with most of the CI values skewed to the right side of the distribution (Supplementary Fig. S1). Based on this frequency distribution of CI values and the threshold value reported by Sallam et al. (2017), a CI of 2.8 was used as the threshold value to differentiate between resistance and susceptibility. The resistant control Q21861 (with resistance genes Rpgl and rpg4/Rpg5) exhibited low ITs ranging from 0;1 (CI = 0.8) to $10 ; 2(\mathrm{CI}=1.6)$. A second resistant control Q/SM20 (with resistance genes rpg 4/Rpg5) also showed low ITs ranging from $0 ; 1$ to 120 ; (CIs of 0.8 to 2.1). The susceptible controls Steptoe and Hiproly reacted as expected, with ITs of $3(\mathrm{CI}=4)$ and $3-$ to $33+$ (CIs of 3.5 to 4.1). Parents MC0181-11, SH98076, and TR02272 exhibited low ITs: 210;, 0; and 1 to 20;, respectively (CIs of 2.5, 0.5, and 1.8, respectively). However, parents MC0181-31 and SB97197 showed high ITs: $3-$ and 23-, respectively (CIs of 3.3 and 3.2, respectively). These values were unexpected considering that Q21861 figures in the pedigrees of these parents and these accessions were described as resistant in prior reports (Steffenson et al. 2017). The parents selected as recipients of TTKSK resistance alleles were susceptible, with ITs ranging from 2 to $3+$ (CIs of 3.4 to 4.1). The most susceptible parental accession was 04_028_36 (CI of 4.1). For the Cycle I population, the highest, lowest, and mean CI values were $4.1,0.5$, and 3.3 , respectively.

Segregation for resistance was observed in all crosses, except those involving MC0181-31 and TR02272 (Table 2). All eight progeny derived from MC0181-31 were susceptible. Only two doubled haploids were derived from TR02272, and the lack of observed segregation could be because of the low sample size. Therefore, the doubled haploid progeny from these two crosses were excluded from subsequent analyses. This led to the final set of 110 doubled haploids used for the analyses described in this report. Crosses involving MC0181-11 gave the highest proportion of resistant progeny ( $31 \%$ of lines being resistant), whereas SH98076 crosses had the highest number of resistant progeny $(n=15)$. The CIs in resistant progeny from these parents ranged from 0.5 to 2.8 . Low numbers ( 3 of 40) of resistant progeny were observed from crosses involving SB97197. Resistant progeny derived from parents MC0181-11 $(n=4)$ and SB97197 $(n=3)$ had the same average CI of 2.4. The CIs of the three doubled haploids derived from SB97197 (DH140270 DH140411, and DH140510) were lower than the CI of SB97197 (2.3, 2.7, and 2.3, respectively, versus 3.2).

If $r p g 4 / R p g 5$ was the sole determinant of resistance to TTKSK, a 1:1 ratio would be expected in $\mathrm{F}_{1}$-derived doubled haploids made from crosses between parents with rpg4/Rpg5 and susceptible parents without rpg4/Rpg5. Considering the doubled haploid progeny of each cross separately, different segregation ratios for resistance/susceptibility were observed. Only progeny from one cross (MC0181-11 $\times$ Full Pint) had an acceptable fit to a 1:1 ratio (Supplementary Table S1).

Considering all progeny derived from each of the resistance donors as distinct subpopulations (Table 3), only the progeny derived from MCO181-11 fit a 1:1 ratio, but there was a better fit to a 1:3 ratio. A 1:3 ratio for resistance:susceptibility was observed in the progeny derived from SH98076. Both 1:1 and 1:3 ratios were rejected for progeny derived from SB97197. When 110 doubled haploids were considered for segregation analysis (excluding the progeny derived from MC0181-31 and TR02272), 22 were classified as resistant, with a CI mean of 2.1 and a range of 0.5 to 2.8. Eighty-eight doubled haploids were classified as susceptible, with a CI mean of 3.7 and a range of 2.9 to 4.1. These data do not fit the $1: 1$ ratio $\left(\chi^{2}=38.76, P=0.00\right)$ expected for segregation of one gene. Rather, the data fit a $1: 3$ ratio $\left(\chi^{2}=1.35, P=0.24\right)$, for which the simplest explanation is independent assortment of alleles at two loci.

Genetics of TTKSK resistance based on $R p g 5$ and $R p g 1$. All parental lines selected as donors of $r p g 4 / R p g 5$ were positive for the Rpg5 (resistance) allele (Table 1). The susceptible parents 04_028_36, Violetta, 10.0691, 10.1151, and Karma generated amplicons with the RpgQ-F6/PP2C-R2 primer combination diagnostic of rpg5 (the susceptibility allele). In the case of Full Pint and Tibet 37, no amplicon was generated using primers targeting the Rpg5 alleles. The phenotypically susceptible parent Oscar has the Rpg5 allele according to the diagnostic primers. However, resequencing revealed a single cytosine insertion resulting in a premature stop codon and therefore, a truncated RPG5 protein as 
described by Arora et al. (2013). All parental germplasm selected as a source of resistance to TTKSK tested positive for the $R p g l$ allele. Three of the TTKSK-susceptible parents (Table 1) amplified for rpgl; the remaining five failed to amplify using Rpgl-specific primers and are, therefore, $\operatorname{rpg} 1$ homozygotes. $\chi^{2}$ tests revealed 1:1 segregation ratios for alleles at the Rpg5 and the Rpg1 loci as determined by allele-specific primers (Table 4 and Supplementary Table S2).

Integrating resistance phenotype and resistance genotype. The allelic state at Rpg5 was not diagnostic of TTKSK resistance: $67 \%(n=43)$ of doubled haploids with $R p g 5$ were susceptible to TTKSK using the CI $>2.8$ criterion. Within the TTKSK-susceptible Rpg 5 types, CI values ranged from 2.9 to 4.0. Within the TTKSKresistant Rpg5 types, CI values ranged from 0.5 to 2.8. All rpg5 types were susceptible: CI values ranged from 3.3 to 4.1 . A $\chi^{2}$ test for independence comparing Rpg5 and rpg5/null marker genotypes for the number of resistant versus susceptible doubled haploids was performed. The result confirms that there are different numbers of resistant and susceptible progeny in the two allele classes $\left(\chi^{2}, 1 \mathrm{df}=\right.$ 21.2, $P<0.001)$. Considering the only cross showing a $1: 1$ segregation ratio (MC0181-11 $\times$ Full Pint), all resistant lines are carrying Rpg5. However, two of three susceptible lines are positive for Rpg5. The allele sequences of the phenotypically susceptible lines with Rpg5 were compared against Q21861 to determine if susceptibility was a result of a nonfunctional RPG5 protein. There were no differences in sequence, confirming that phenotypically susceptible lines have the same Rpg5 allele present in Q21861. Considering Rpgl, there were 60 doubled haploids with the Rpg1 allele: 9 were phenotypically resistant to TTKSK. There were 57 doubled haploids with the rpgl or null alleles, and 12 were phenotypically resistant to TTKSK. All of the resistant lines considered in the analysis of Rpgl are carrying the resistant Rpg5 allele. The $\chi^{2}$ test for independence comparing $R p g l$ and $r p g 1 /$ null marker genotypes for the number of resistant versus susceptible doubled haploids was not significant $\left(\chi^{2}, 1 \mathrm{df}=0.72, P=0.39\right)$. These results indicate that Rpgl is not a determinant of resistance to TTKSK in the Cycle I population.

TTKSK resistance at the adult plant stage. In 2016, extremely low rust severities at Njoro precluded obtaining any meaningful data on the germplasm. In 2017, doubled haploids that were resistant at the seedling stage showed moderate to high levels of resistance at the adult plant stage, with disease severities ranging from 1 to $20 \%$ (Supplementary Table S3). The parents were not included in this trial. One doubled haploid (DH140410) had a disease severity of $40 \%$. This doubled haploid is rpg5rpg 5 and has an average CI of 3.3. A second doubled haploid (DH140508) had a disease severity of $30 \%$ and was Rpg5Rpg 5 with a seedling CI of 3.4 .

Resistance to other diseases. A range of responses to stripe rust were observed in the 117 doubled haploids evaluated in multilocation field trials. Data are available at https://barleyworld. org/barley-stripe-rust-bsr (accessed April 2018). Doubled haploids exhibiting resistance to all three rusts are shown in Table 5.

Association analysis. None of the statistical transformations improved the normality of the data based on the results of the Shapiro-Wilk test. Therefore, GWAS analysis was performed on untransformed CI means. The first three PCs-explaining 34\% of the genetic variation-were incorporated into GWAS model. The first two PCs explained 18.5 and $9.7 \%$ of the genetic variation, respectively (Supplementary Fig. S2). The comparison between observed and expected association $P$ values in a quantile-quantile plot is shown in Supplementary Figure S3. Using an FDR threshold of $5 \%$, nine significant marker-trait associations were detected in the Cycle I population (Fig. 1 and Supplementary Table S4). The significant markers (SCRI_RS_192640, SCRI_RS_168091, SCRI_RS_181059, SCRI_RS_168668, BOPA2_12_30716, SCRI_RS_165835, SCRI_RS_2824, BOPA1_5428-146, and SCRI_RS_1458) map to an $\sim 5$-Mb region $(638$ to $643 \mathrm{Mb}$ ) on chromosome 5H (Mascher et al. 2017). This region corresponds to a 4.4-cM region on the consensus linkage map of Muñoz-Amatriaín et al. (2014) from 153.8 to $158.2 \mathrm{cM}$. The rpg4/Rpg5 locus is in this interval according to the alignment of the consensus map and the barley genome sequence (Mascher et al. 2017; Muñoz-Amatriaín et al. 2014). The most significant marker was SCRI_RS_192640, which explained $24 \%$ of phenotypic variation, and is in linkage disequilibrium with the other significant markers in the significant interval $\left(R^{2}>0.7\right)$.

Hypothesizing that we could not detect minor QTLs that could account for the lack of fit to the expected 1:1 ratio and the TTKSKsusceptible lines with the Rpg5 allele owing to the small sample size of the Cycle I population, we used a 10\% FDR threshold to detect additional loci. At this FDR, 16 additional SNPs were significantly associated with stem rust resistance. Of these, 13 are in the same genome region as those associated with rpg4/Rpg 5 at 5\% FDR (Fig. 1). We found two additional significant regions on chromosomes $5 \mathrm{H}$ and $7 \mathrm{H}$. The $5 \mathrm{H}$ region included one significant SNP (BOPA1_3333-1209) located at $\sim 542 \mathrm{Mb}(76.3 \mathrm{cM})$, and it accounted for $11 \%$ of the phenotypic variation. Two significant

TABLE 3. $\chi^{2}$ tests for coefficient of infection at the seedling stage in the TTKSK Cycle I population ${ }^{\mathrm{a}}$

\begin{tabular}{|c|c|c|c|c|c|c|c|}
\hline \multirow[b]{2}{*}{ Pedigree $^{b}$} & \multicolumn{3}{|c|}{ Number of DH lines } & \multicolumn{2}{|r|}{$1: 1$} & \multicolumn{2}{|r|}{$1: 3$} \\
\hline & Total & Resistant & Susceptible & $\chi^{2}$ & Probability $\left(>\chi^{2}\right)$ & $\chi^{2}$ & Probability $\left(>\chi^{2}\right)$ \\
\hline All & 110 & 22 & 88 & 38.76 & 0.00 & 1.35 & 0.24 \\
\hline MC0181-11 × & 13 & 4 & 9 & 1.92 & 0.16 & 0.23 & 0.63 \\
\hline SB97197 × _ & 40 & 3 & 37 & 28.90 & 0.00 & 6.53 & 0.01 \\
\hline
\end{tabular}

a Doubled haploids (DHs) from each pedigree are classified as resistant or susceptible based on a coefficient of infection threshold of 2.8 .

b Progeny from parents MC0181-31 and TR02272 were excluded from the $\chi^{2}$ test.

${ }^{c}$ One DH with phenotype but no genotypic information was included for segregating analysis.

TABLE 4. $\chi^{2}$ tests for allele-specific markers targeting Rpg5 and Rpg1 in the TTKSK Cycle I population

\begin{tabular}{|c|c|c|c|c|c|c|c|c|c|c|}
\hline \multirow[b]{2}{*}{ Type } & \multicolumn{3}{|c|}{ Number of DH lines ${ }^{\mathrm{a}}$} & \multicolumn{2}{|r|}{$1: 1$} & \multicolumn{3}{|c|}{ Number of DH lines } & \multicolumn{2}{|r|}{$1: 1$} \\
\hline & Rpg5 & rpg 5 & Null & $\chi^{2}$ & Probability $\left(>\chi^{2}\right)$ & Rpg1 & rpgl & Null & $\chi^{2}$ & Probability $\left(>\chi^{2}\right)$ \\
\hline Resistant & 21 & 0 & 0 & & & 9 & 2 & 10 & & \\
\hline Susceptible & 43 & 40 & 13 & & & 51 & 21 & 24 & & \\
\hline
\end{tabular}

a In total, 117 and 119 doubled haploids (DHs) were genotyped for Rpg5 and Rpg1, respectively. 
SNPs (SCRI_RS_149709 and BOPA2_12_20832) mapped to 134.9 $\mathrm{cM}(\sim 629 \mathrm{Mb})$. Each accounted for $10 \%$ of the phenotypic variation.

Subsequently, following the example of Lipka et al. (2013, 2015), we chose a subset of 2,030 SNPs mapping to regions of the genome where QTLs associated with resistance to multiple rusts are reported (chromosomes $4 \mathrm{H}, 5 \mathrm{H}$, and $7 \mathrm{H})($ Castro et al. 2003a; Chen et al. 1994; Gutiérrez et al. 2015; Hayes et al. 1996). Using this approach, we identified three regions containing 25 SNPs significantly associated with resistance to TTKSK at the seedling stage. These regions coincide with those identified on $5 \mathrm{H}$ and $7 \mathrm{H}$ using all marker data and an FDR threshold of $10 \%$. There were no significant SNPs detected on chromosome $4 \mathrm{H}$ with either approach.

Individual and joint effects of marker alleles on the TTKSK seedling resistance phenotype. The doubled haploids in the Cycle I population were assigned to groups defined by the combinations of alleles at Rpg 5 and the $5 \mathrm{H}$ and $7 \mathrm{H}$ QTLs (Fig. 2). In Figure 2, + and - indicate resistance and susceptibility alleles at QTLs, respectively. The combination of the three most significant SNPs accounted for $45 \%$ of the phenotypic variation in stem rust resistance. The allele combination $R p g 5 / 7 \mathrm{H}+/ 5 \mathrm{H}+$ had the lowest mean CI (2.4) and was present in 25 doubled haploids. The highest mean CI (3.9) was found in the 32 doubled haploids with the rpg5/ $7 \mathrm{H}+/ 5 \mathrm{H}$ - haplotype. The mean CI of the doubled haploids with the $R p g 5 / 7 \mathrm{H}+/ 5 \mathrm{H}+$ haplotype was significantly lower than that of any other combination of alleles at the three loci. The TTKSK-resistant parents were also $R p g 5 / 7 \mathrm{H}+/ 5 \mathrm{H}+$, except for $\mathrm{MC} 0181-31$ and TR02272, which had the - allele at the 5H QTL. The ratio of Rpg5/ $7 \mathrm{H}+/ 5 \mathrm{H}+$ to all other allele combinations $(25: 94)$ fits a $1: 3$ ratio $\left(\chi^{2}\right.$ $=1.01, P=0.31)$. There were approximately equal numbers of doubled haploids in four of the haplotype classes, fewer in two classes, and none in two classes. These deviations from the expected eight classes were owing to the low frequency of - alleles at the $7 \mathrm{H}$ QTL. When an ANOVA was performed using the most significant SNPs at each QTL, the $F$ statistics were significant for Rpg5, the quantitative trait locus on $5 \mathrm{H}$ (QTL5), and the quantitative trait locus on 7H (QTL7). Significant interactions were detected for $R p g 5 \times$ QTL5 and Rgp5 × QTL7. The lack of QTL5 $\times$ QTL7 and Rpg $5 \times$ QTL5 $\times$ QTL7 genotypes did not allow for testing the significance of these interactions (Supplementary Table S5).

\section{DISCUSSION}

We implemented a defensive breeding strategy to prepare barley producers and users for the eventual arrival of stem rust race TTKSK to North America. In this region, barley crops have been protected against stem rust epidemics by Rpgl (Steffenson 1992), but this gene does not confer resistance to TTKSK (Steffenson and
Jin 2006; Steffenson et al. 2009). Moreover, there are few sources of resistance to TTKSK: of 1,924 barley accessions screened for seedling resistance, $<5 \%$ were highly or moderately resistant (Steffenson et al. 2017). Although several QTLs have been reported that confer varying degrees of resistance to TTKSK, only rpg4/ $R p g 5$ provides high levels of resistance at the seedling and adult stages (Mamo et al. 2015; Moscou et al. 2011; Steffenson et al. 2009). Jin et al. (1994b) first reported line Q21861, originally from the International Center for Agricultural Research in the Dry Areas (ICARDA)/CIMMYT program in Mexico, as a source of resistance to race QCC (now designed QCCJB) of stem rust. Breeding programs based in Manitoba and Saskatchewan, Canada quickly took advantage of the reported resistance of Q21861 to QCCJB and introgressed the resistance into agronomically competitive backgrounds. These new carriers of the Q21861 resistance are two row, have spring growth habit, and include both covered (hulled) and naked (hulless) types (with and without adhering hulls, respectively). The resistance to race QCCJB was subsequently found to cosegregate with the rpg4/Rpg5 resistance to race TTKSK (Steffenson et al. 2009). Our goal was to introgress the rpg4/Rpg5 complex from the Canadian germplasm into a broader array of accessions representing a range of growth habits (spring, facultative, and winter) and end uses (malting and food).

At the outset, this seemed to be a relatively straightforward exercise involving alleles at a complex locus that behaved as a single Mendelian factor. There was the additional benefit of a perfect allele-specific marker for Rpg5 to track inheritance. We were optimistic that the Cycle I population could have breeding value and be of assistance in higher-resolution analysis of the relationship of $r p g 4 / R p g 5$ with different genetic backgrounds. Phenotyping for TTKSK resistance was available thanks to the extensive collaborative infrastructure provided by the BSL-3 Containment Facility at the University of Minnesota for seedling assessments and the Kenya nurseries, coordinated by the USDAARS, for confirming adult plant resistance. We were able to transfer and detect the presence of rpg4/Rpg 5 in doubled haploid progeny derived from crosses between donors of resistance and susceptible recipient parents. However, we encountered unexpected phenotypes in some resistance donors and phenotypic ratios in the progeny that did not support monofactorial inheritance. These discoveries provided opportunities to assess the role of known genes in different genetic backgrounds and to design and implement effective breeding strategies for resistance to TTKSK and other diseases in barley.

The donors selected as resistant, all with the resistance allele at the Rpg 5 locus validated by allele-specific genotyping, exhibited a range of responses when phenotyped for TTKSK at seedling stage.

TABLE 5. Selected doubled haploids from the TTKSK Cycle I population with resistance to stripe rust (incited by Puccinia striiformis f. sp. hordei), leaf rust (incited by Puccinia hordei), and TTKSK stem rust (incited by Puccinia graminis f. sp. tritici)

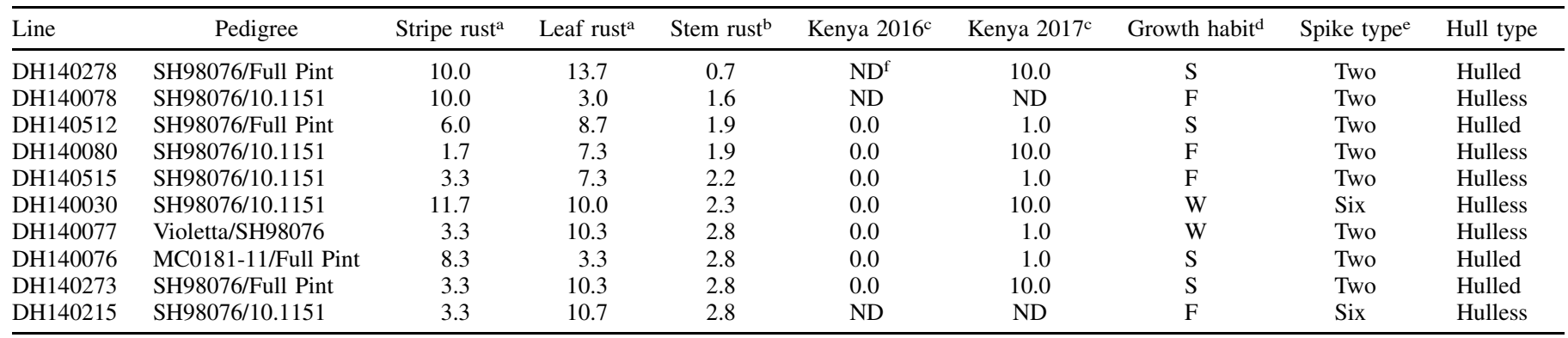

a Disease severity expressed as percentage. Data were collected in field evaluations in Corvallis, Oregon; Davis, California; and Mount Vernon, Washington.

b Coefficient of infection based on infection type as described by Zhou et al. (2014). Data were collected in a Biosafety Level 3 Containment Facility at the University of Minnesota.

${ }^{c}$ Field stem rust evaluations in the field. Disease severity is expressed as a percentage.

${ }^{\mathrm{d}} \mathrm{F}$ indicates facultative, $\mathrm{S}$ indicates spring, and $\mathrm{W}$ indicates winter.

e Two indicates that only central spikelets are fertile, and six indicates that all spikelets are fertile (Komatsuda et al. 2007).

${ }^{f} \mathrm{ND}$ indicates no data for lines in that year. 
Three (MC0181-11, SH98076, and TR02272) were highly resistant. Two (MC0181-31 and SB97197) were moderately susceptible. The latter result was surprising given that members of our research team had observed, in previous studies, highly resistant reactions in all donors at the seedling stage (Steffenson et al. 2017). We found that MC0181-31 and the 10 doubled haploids derived from crosses with it were susceptible. We can rule out inadvertent selfing in the process of crossing based on several lines of evidence. The doubled haploids derived from MC0181-31 segregated for Rpg1, a locus at which only MC0181-31 has the dominant allele. Haplotype inspection and resequencing provided additional evidence that the presumed $F_{1}$ plants used for doubled haploid production were indeed $\mathrm{F}_{1}$. Analysis of progeny with Violetta as the other parent revealed the susceptible haplotype at markers in the genome region where rpg4/Rpg5 is located. When genome regions corresponding to QTLs on $5 \mathrm{H}$ and $7 \mathrm{H}$ were analyzed, haplotypes from both parents were found, validating parentage. The larger number of doubled haploids $(n=40)$ produced from crosses with SB97197 compared with those from crosses involving MCO181-31 $(n=8)$ provided a greater opportunity to explore the inheritance of resistance to TTKSK. Three doubled haploids with greater resistance than the donor parent were recovered, suggesting that an additional resistance allele is involved in this genetic background and that this allele traces to the susceptible parent 04_028_36. The implication is that moderately susceptible genotypes may have "unexpected" resistance alleles and that these alleles may account for observed patterns of transgressive segregation. These findings on the level of resistance conferred by rgp4/Rpg 5 tracing to Q21861 when deployed in different genetic backgrounds can afford geneticists paths to explore regarding the role of genetic background on the effects of "major" resistance genes.

Analysis of phenotypic data in the Cycle I population leads to the hypothesis that rpg4/Rpg5 is necessary but is not sufficient to confer resistance to race TTKSK: $67 \%(n=43)$ of doubled haploid lines carrying the Rpg 5 allele were susceptible. Variation in IT, ranging from 0 ; to 2, has been found in landraces and wild types carrying the Rpg5 allele associated with resistance (Steffenson et al. 2017). The existence of additional genes beyond rpg4/Rpg5 is supported by previous research using different generation types for genetic analysis. Jin et al. (1994a) used $\mathrm{F}_{2}$ populations derived from Q21861 crosses and reported 1:3 segregation ratios for resistance/ susceptibility in some of these populations. This was essential in confirming the recessive nature of rpg4. In this study, considering all cross progeny, the best fit was also a 1:3 ratio. However, in

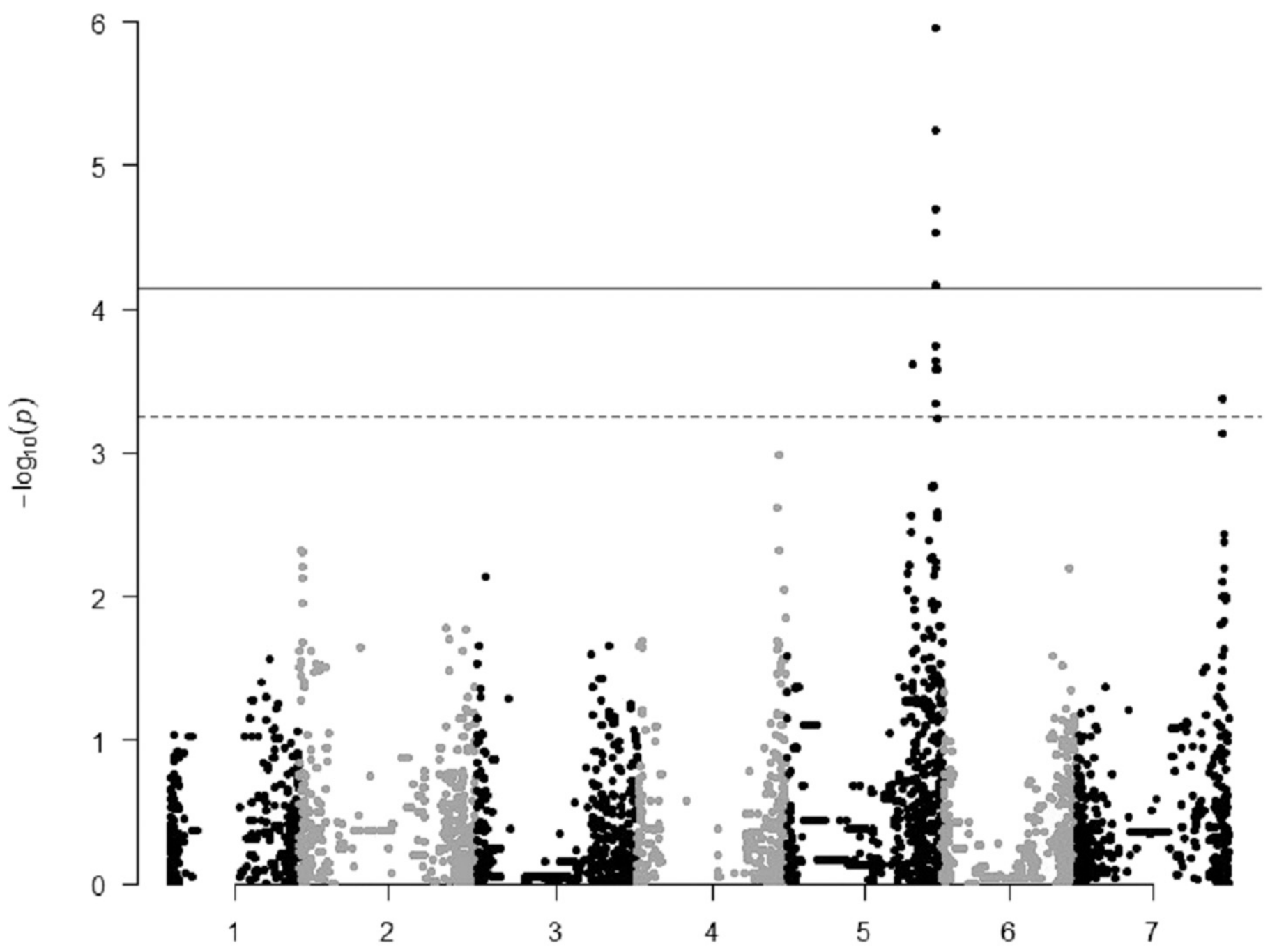

\section{Chromosome}

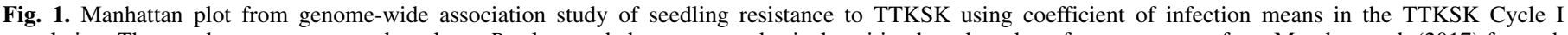

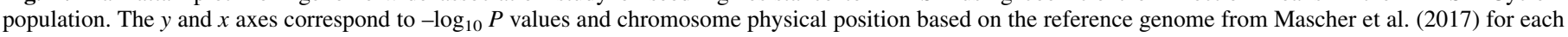

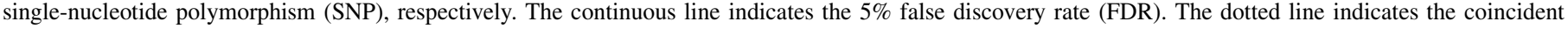
threshold levels at $10 \%$ FDR using all SNPs and at 5\% FDR using a subset of SNPs. 
doubled haploids (as opposed to $\mathrm{F}_{2}$ ), this ratio suggests in the simplest interpretation the additive effects of alleles at two unlinked loci. There are reports in the literature that the $\operatorname{rgp} 4 / \mathrm{Rpg} 5$ alleles may require additional genetic factors to confer resistance to TTKSK. Jin et al. (1994a) found that, in some $F_{2}$ populations, there was a 1:15 ratio of resistance/susceptibility to race QCCJB, suggesting two unlinked recessive genes associated with resistance. Mamo et al. (2015) reported that the $F_{3}$ families from crosses segregating for Rpg5 did not fit a 1:2:1 ratio for resistance to race TTKSK, suggesting that more than one gene is conferring resistance. Evaluating resistance to race QCCJB under field conditions using $\mathrm{F}_{3}$ lines derived from the cross Hiproly-15 $\times$ Q21861, Fox and Harder (1995) also reported a segregation ratio of 1:15. Sharma Poudel et al. (2018) also reported additional factors required for rpg4-mediated resistance. Cumulatively, these reports and the results from this study, point to an essential role for another gene (or genes) if rpg4/Rpg 5 is to confer a high level of resistance to TTKSK. The $\mathrm{F}_{2}$ and $\mathrm{F}_{3}$ data from the prior reports suggest that resistance at the unknown locus (or loci) is controlled by recessive alleles.

Identifying the other gene (or genes) is essential for a complete understanding of the genetic basis of resistance to TTKSK and effective MAS. Using GWAS, we detected associations of SNP markers with seedling resistance to TTKSK at genomic regions different from those for $r p g 4 / R p g 5$. These associations approached the 5\% FDR using all markers and exceeded the 5\% FDR when we targeted a subset of markers reported in the literature to be associated with resistance to stem rust, leaf rust, and stripe rust. Although small populations, such as the one used for this study, have been used successfully for GWAS (Galeano et al. 2012; Gutiérrez et al. 2011; Wang et al. 2011), the power to detect a significant true association between a trait and a genotype is a function of allele frequency and population size (Long and Langley 1999; Myles et al. 2009). In our case, population size is certainly an issue affecting capacity to detect associations at the generally accepted FDR of 5\%. Also, the low frequency of the - allele on $7 \mathrm{H}$ is affecting the capacity to detect significance for this minor QTL. Support for the possible biological relevance of the QTLs on $5 \mathrm{H}$ and $7 \mathrm{H}$ comes from (i) the resistance mapping literature, (ii) phenotypic classification of Cycle I doubled haploids based on haplotypes at rpg4/Rpg5 and the two QTLs, and (iii) candidate genes coincident with the $5 \mathrm{H}$ and $7 \mathrm{H}$ QTLs.

Using the consensus map of Muñoz-Amatriaín et al. (2014), the putative QTL detected on chromosome $5 \mathrm{H}$ is at 73.1 to $76.3 \mathrm{cM}$ ( $\sim 541 \mathrm{Mb})$. Case et al. (2018b) and Zhou et al. (2014) used GWAS to map QTLs associated with TTKSK resistance at both adult and seedling plant stages and reported significant marker-trait associations. Using the significant markers that they reported and the consensus map of Muñoz-Amatriaín et al. (2014), these QTLs are at 68.5 to $71.5 \mathrm{cM}(\sim 532 \mathrm{Mb})$ on $5 \mathrm{H}$. Mamo et al. (2015) reported a seedling-stage resistance QTL at $88.8 \mathrm{cM}(\sim 561 \mathrm{Mb})$ as determined using the same consensus mapping process. Moscou et al. (2011), using a biparental doubled haploid population, reported an adult plant resistance QTL at $74.9 \mathrm{cM}$. Case et al. (2018a), using a

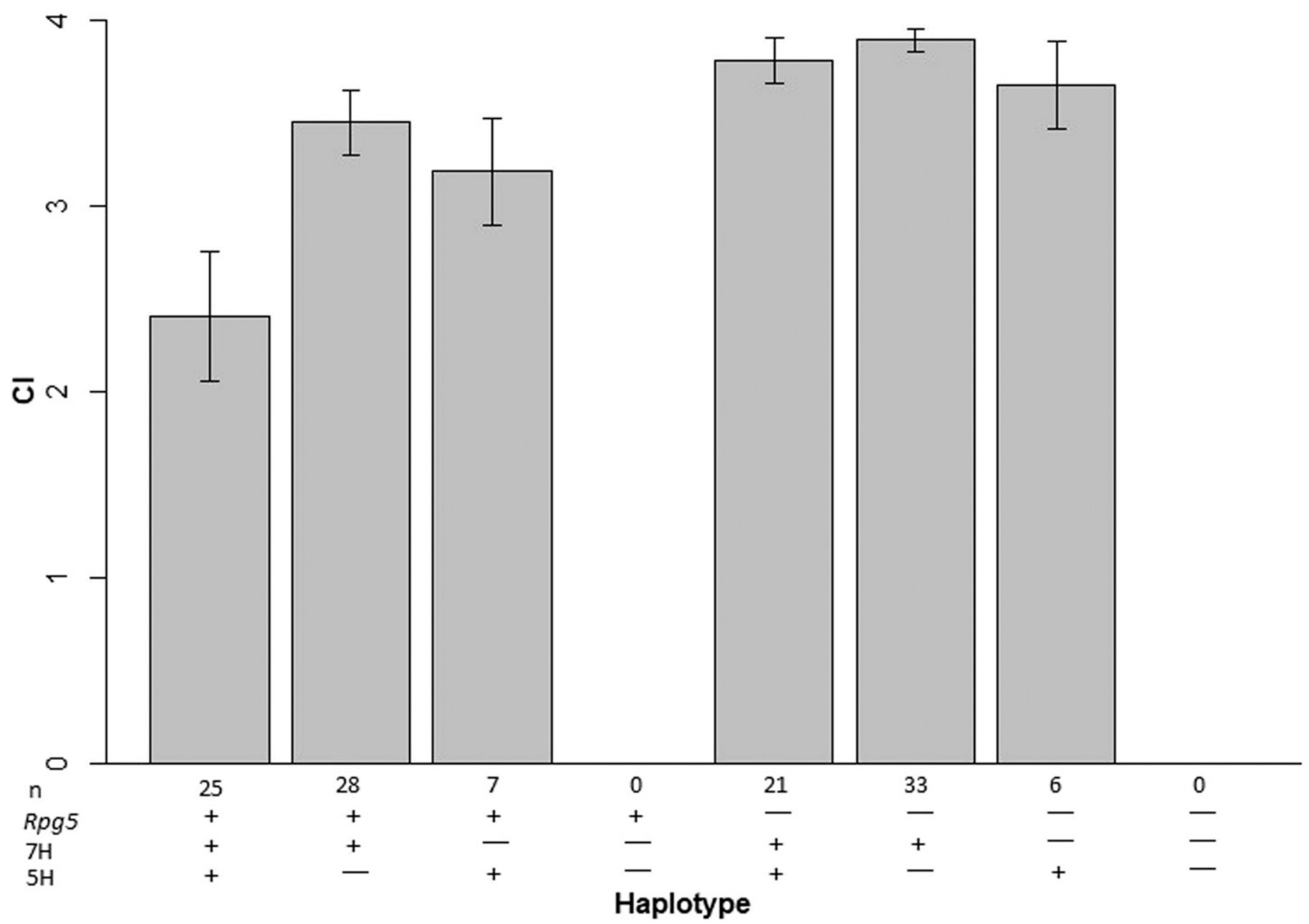

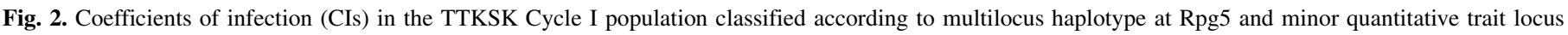

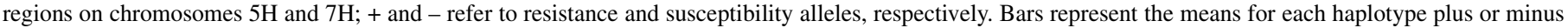
standard error. 
biparental population derived from resistant parent PI382313 and susceptible parent Hiproly, found the most significant QTL for stem rust resistance at 74 to $86 \mathrm{cM}$ on chromosome $5 \mathrm{H}$ and hypothesized that this could be owing to Rpg3. This locus could not be placed on the consensus map because of a lack of common markers. Required for rpg4-mediated resistance 1 was mapped to the telomeric region of $5 \mathrm{H}(153.47 \mathrm{cM})$ in the progeny of Pinnacle and Q2186 (Sharma Poudel et al. 2018). On chromosome 7H (long arm), we detected a putative QTL at $135 \mathrm{cM}(\sim 629 \mathrm{Mb})$. There are reports in the literature of QTLs related to resistance to TTKSK on chromosome 7H (Moscou et al. 2011; Sallam et al. 2017; Zhou et al. 2014) but not coincident with the QTL that we detected. There are also reports of genes/QTLs on $7 \mathrm{H}$ at the same chromosome arm position as the QTL that we detected related to resistance to stripe rust, leaf rust, and other races of stem rust (Castro et al. 2003a; Chen et al. 1994; Gutiérrez et al. 2015; Hayes et al. 1996; Rossi et al. 2006). The coincidence of genes/QTLs conferring plant resistance to multiple specificities of the same pathogen or different pathogens has been previously reported (Inukai et al. 2006; Sato et al. 2001).

The classification of the Cycle I population based on allele composition at Rpg5 and two QTLs explains the observed phenotypic segregation ratio for TTKSK resistance of one resistant to three susceptible. These results also support the phenotypic classification system (resistant doubled haploids defined as $\mathrm{CI} \leq$ 2.8). Steffenson et al. (2017) reported that the effects of rpg4/Rpg 5 and other major genes conferring resistance to rusts can be affected by environmental signals (e.g., temperature), epidemiological considerations (e.g., disease pressure), and genetic background. In the Cycle I population, the highest level of resistance was observed in doubled haploids carrying the resistant allele at Rpg5 and specific inferred alleles at the additional $5 \mathrm{H}$ QTL and the $7 \mathrm{H}$ QTL. All other combinations were significantly more susceptible than the most resistant haplotype. The lack of doubled haploids with $\mathrm{a}$-allele at the 7H QTL suggests that some susceptible parents may have + alleles at this locus. From a plant breeding perspective, introgression of resistance alleles based only on genetic information is an attractive proposition. However, introgression of major resistance genes into a diversity of genetic backgrounds can reveal previously unknown loci with roles in resistance. MAS for specific loci known to be essential for resistance-such as rpg4/Rpg5-can thus be a useful screening tool, but phenotypic validation is essential and can assist in revealing additional genes in the resistance pathway.

Survey of a 2-Mb region surrounding significant SNPs from the $5 \mathrm{H}$ and $7 \mathrm{H}$ QTL regions based on the barley reference genome sequence (Mascher et al. 2017) revealed 15 high-confidence gene models with annotations related to disease resistance. On chromosome 5H, BOPA1_3333-1209 is contained in HORVU5Hr1G074340.2, a gene annotated as a chitinase family protein. Chitinases play a major role in plant defense (Xu et al. 2016) and are reported to be associated with resistance to fungal diseases in barley, peanut, and banana (Backiyarani et al. 2015; Chen et al. 2010; Grover 2012; Prasad et al. 2013). On chromosome 7H, SCRI_RS_149709 is located in HORVU7Hr1G110200.15, a gene encoding a transmembrane protein receptor-like kinase. Transmembrane protein kinases participate in a diverse range of processes, including disease resistance (Shiu and Bleecker 2001), and they are associated with pathogen resistance in rice and tomato (Sessa and Martin 2000; Song et al. 1995). This candidate gene search provides support for the biological relevance of the detected QTLs, although deeper characterization is essential before cause-effect relationships are established. Candidate genes and adjoining sequences can also enrich the number of markers in target regions. The availability of candidate gene, QTL, and cloned gene information can assist in achieving the long-term goal of durable resistance to rusts in cereal crops. Introgression of rpg4/Rpg5-together with the $5 \mathrm{H}$ and $7 \mathrm{H}$ QTL alleles-is a first step.
Validation of seedling resistance at the adult plant stage is essential. In the case of race TTKSK, this is hard to achieve because of the limited numbers of lines that can be tested in the Kenya nurseries and the reliance on environmental conditions favoring epidemic development. It is encouraging that doubled haploids resistant at the seedling stage with $R p g 5$ are also resistant at the adult stage. Doubled haploid (DH140508) has Rpg5, but it was rated susceptible at the seedling stage $(\mathrm{CI}=3.4)$, evidence that genotyping for Rpg5 without phenotyping will not always select for TTKSK resistance.

Pyramiding additional major genes and QTLs is the next step: successful examples for other plant diseases have been described (reviewed by Pilet-Nayel et al. [2017]). Pyramiding can also assist in increasing the overall level and spectrum of disease resistance, ultimately leading to broad-spectrum resistance (Friedt and Ordon 2007). For example, although Rpg1 is not directly associated with TTKSK resistance, its presence may trigger residual resistance to TTKSK and other rusts (Steffenson et al. 2017). More broadly, multiple diseases are likely to threaten crop production in any given environment. For example, barley stripe rust is an important disease in the Pacific Northwest of the United States (Line 2002), and leaf rust is becoming increasingly prevalent in the region. We, therefore, screened the Cycle I population for adult plant resistance to stripe and leaf rust in multienvironment field trials and identified doubled haploids with resistance to TTKSK and these other rusts (Table 5 and Supplementary Table S6).

This study underscores the importance of germplasm and data exchange to meet the challenges of current and emerging diseases while at the same time, developing varieties that meet quality and agronomic expectations. For example, Q21861 was first reported as a source of resistance to stem rust QCCJB in 1994 (Jin et al. 1994a). Subsequently, Sun et al. (1996) found that this accession confers resistance to $P$. graminis $\mathrm{f}$. sp. secalis isolate $92-\mathrm{MN}-90$. This resistance cosegregated with resistance to race QCCJB. Brueggeman et al. (2008) found that the rpg4/Rpg 5 complex locus consists of four genes and that rpg4 and Rpg5 are required to confer resistance to QCCJB, although Rpg5 is required for resistance to rye stem rust. Then, Steffenson et al. (2009) found that resistance to TTKSK cosegregated with resistance to QCCJB and 92-MN-90. This resistance was then introgressed into adapted genetic backgrounds (A. Beattie, B. Legge, and B. Rossnagel, personal communication). The work of Arora et al. (2013) and Brueggeman et al. (2008) led to the development of a perfect marker for Rpg5. Meanwhile, the international barley community developed genomics resources, including SNP arrays (Close et al. 2009), consensus maps (MuñozAmatriaín et al. 2011, 2014), and a reference genome sequence (Mascher et al. 2017). Twenty-four years after the initiation of this process, we provide this Cycle I germplasm characterized at the phenotypic and genotypic levels as a community resource for continued genetic analysis and breeding.

\section{ACKNOWLEDGMENTS}

We thank Shiaoman Chao (retired; U.S. Department of Agriculture Agricultural Research Service, Fargo, ND) for Illumina 9K genotyping and allele calling, Rick Gadzinski and Sean Tracey at Functional Biosciences for genotyping and resequencing related to Rpg1 and Rpg5, Austin Case for excellent technical assistance and phenotyping for TTKSK in the Biosafety Level-3 Containment Facility at the University of Minnesota in St. Paul, and the funding received from Comisión Nacional de Investigación Científica y Tecnológica (CONICYT) Becas-Chile 72160554.

\section{LITERATURE CITED}

Arora, D., Gross, T., and Brueggeman, R. 2013. Allele characterization of genes required for $r p g 4$-mediated wheat stem rust resistance identifies Rpg5 as the R gene. Phytopathology 103:1153-1161.

Arunakumari, K., Durgarani, C., Satturu, V., Sarikonda, K., Chittoor, P., Vutukuri, B., Laha, G., Nelli, A., Gattu, S., and Jamal, M. 2016. Marker-assisted 
pyramiding of genes conferring resistance against bacterial blight and blast diseases into Indian rice variety MTU1010. Rice Sci. 23:306-316.

Backiyarani, S., Uma, S., Nithya, S., Chandrasekar, A., Saraswathi, M., Thangavelu, R., Mayilvaganan, M., Sundararaju, P., and Singh, N. 2015. Genome-wide analysis and differential expression of chitinases in banana against root lesion nematode (Pratylenchus coffeae) and eumusa leaf spot (Mycosphaerella eumusae) pathogens. Appl. Biochem. Biotechnol. 175: 3585-3598.

Benjamini, Y., and Hochberg, Y. 1995. Controlling the false discovery rate: A practical and powerful approach to multiple testing. J. R. Stat. Soc. Series B Stat. Methodol. 57:289-300.

Bilgic, H., Steffenson, B., and Hayes, P. 2005. Comprehensive genetic analyses reveal differential expression of spot blotch resistance in four populations of barley. Theor. Appl. Genet. 111:1238-1250.

Bradbury, P. J., Zhang, Z., Kroon, D. E., Casstevens, T. M., Ramdoss, Y., and Buckler, E. S. 2007. TASSEL: Software for association mapping of complex traits in diverse samples. Bioinformatics 23:2633-2635.

Brueggeman, R., Druka, A., Nirmala, J., Cavileer, T., Drader, T., Rostoks, N., Mirlohi, A., Bennypaul, H., Gill, U., and Kudrna, D. 2008. The stem rust resistance gene Rpg5 encodes a protein with nucleotide-binding-site, leucine-rich, and protein kinase domains. Proc. Natl. Acad. Sci. USA 105: 14970-14975

Case, A. J., Bhavani, S., Macharia, G., Pretorius, Z., Coetzee, V., Kloppers, F., Tyagi, P., Brown-Guedira, G., and Steffenson, B. J. 2018a. Mapping adult plant stem rust resistance in barley accessions Hietpas-5 and GAW-79. Theor. Appl. Genet. 131:1-22.

Case, A. J., Bhavani, S., Macharia, G., and Steffenson, B. J. 2018b. Genomewide association study of stem rust resistance in a world collection of cultivated barley. Theor. Appl. Genet. 131:107-126.

Castro, A., Capettini, F., Corey, A., Filichkina, T., Hayes, P., Kleinhofs, A., Kudrna, D., Richardson, K., Sandoval-Islas, S., and Rossi, C. 2003a. Mapping and pyramiding of qualitative and quantitative resistance to stripe rust in barley. Theor. Appl. Genet. 107:922-930.

Castro, A. J., Chen, X., Hayes, P. M., and Johnston, M. 2003b. Pyramiding quantitative trait locus (QTL) alleles determining resistance to barley stripe rust. Crop Sci. 43:651-659.

Chen, F., Prehn, D., Hayes, P., Mulrooney, D., Corey, A., and Vivar, H. 1994. Mapping genes for resistance to barley stripe rust (Puccinia striiformis $\mathrm{f}$. $\mathrm{sp}$. hordei). Theor. Appl. Genet. 88:215-219.

Chen, X., Niks, R. E., Hedley, P. E., Morris, J., Druka, A., Marcel, T. C., Vels, A., and Waugh, R. 2010. Differential gene expression in nearly isogenic lines with QTL for partial resistance to Puccinia hordei in barley. BMC Genomics 11:629.

Cistué, L., Cuesta-Marcos, A., Chao, S., Echávarri, B., Chutimanitsakun, Y., Corey, A., Filichkina, T., Garcia-Marino, N., Romagosa, I., and Hayes, P. 2011. Comparative mapping of the Oregon Wolfe Barley using doubled haploid lines derived from female and male gametes. Theor. Appl. Genet. 122:1399-1410.

Close, T. J., Bhat, P. R., Lonardi, S., Wu, Y., Rostoks, N., Ramsay, L., Druka, A., Stein, N., Svensson, J. T., and Wanamaker, S. 2009. Development and implementation of high-throughput SNP genotyping in barley. BMC Genomics 10:582.

Comadran, J., Kilian, B., Russell, J., Ramsay, L., Stein, N., Ganal, M., Shaw, P., Bayer, M., Thomas, W., and Marshall, D. 2012. Natural variation in a homolog of Antirrhinum CENTRORADIALIS contributed to spring growth habit and environmental adaptation in cultivated barley. Nat. Genet. 44: 1388-1392.

Derevnina, L., Fetch, T., Singh, D., Brueggeman, R., Dong, C., and Park, R. 2014. Analysis of stem rust resistance in Australian barley cultivars. Plant Dis. 98:1485-1493.

Eckstein, P., Rossnagel, B., and Scoles, G. 2003. Allele-specific markers within the barley stem rust resistance gene (Rpg1). Barley Genet. Newsl. 33:7-11.

Edae, E. A., Pumphrey, M. O., and Rouse, M. N. 2018. A genome-wide association study of field and seedling response to individual stem rust pathogen races reveals combinations of race-specific genes in North American spring wheat. Front. Plant Sci. 9:52.

FAOSTAT. 2014. Production and Trade. Food and Agriculture Organization of the United Nations. FAO-STAT. 2014. Production and Trade. FAO. Rome, Italy.

Fox, S., and Harder, D. 1995. Resistance to stem rust in barley and inheritance of resistance to race QCC. Can. J. Plant Sci. 75:781-788.

Friedt, W., and Ordon, F. 2007. Molecular markers for gene pyramiding and disease resistance breeding in barley. Pages 81-101 in: Genomics-Assisted Crop Improvement. R. Varshney and R. Tuberosa, eds. Springer, New York.

Galeano, C. H., Cortés, A. J., Fernández, A. C., Soler, Á., Franco-Herrera, N., Makunde, G., Vanderleyden, J., and Blair, M. W. 2012. Gene-based single nucleotide polymorphism markers for genetic and association mapping in common bean. BMC Genet. 13:48.

Grover, A. 2012. Plant chitinases: Genetic diversity and physiological roles. Crit. Rev. Plant Sci. 31:57-73.
Gutiérrez, L., Cuesta-Marcos, A., Castro, A. J., von Zitzewitz, J., Schmitt, M., and Hayes, P. M. 2011. Association mapping of malting quality quantitative trait loci in winter barley: Positive signals from small germplasm arrays. Plant Genome 4:256-272.

Gutiérrez, L., Germán, S., Pereyra, S., Hayes, P. M., Pérez, C. A., Capettini, F., Locatelli, A., Berberian, N. M., Falconi, E. E., and Estrada, R. 2015. Multienvironment multi-QTL association mapping identifies disease resistance QTL in barley germplasm from Latin America. Theor. Appl. Genet. 128: 501-516.

Hayes, P., Prehn, D., Vivar, H., Blake, T., Comeau, A., Henry, I., Johnston, M., Jones, B., Steffenson, B., and St. Pierre, C. 1996. Multiple disease resistance loci and their relationship to agronomic and quality loci in a spring barley population. J. Agric. Genomics 2:1-9.

Inukai, T., Vales, M. I., Hori, K., Sato, K., and Hayes, P. M. 2006. RMo 1 confers blast resistance in barley and is located within the complex of resistance genes containing Mla, a powdery mildew resistance gene. Mol. Plant-Microbe Interact. 19:1034-1041.

Jin, Y., and Singh, R. 2006. Resistance in US wheat to recent eastern African isolates of Puccinia graminis f. sp. tritici with virulence to resistance gene Sr31. Plant Dis. 90:476-480.

Jin, Y., Steffenson, B., and Miller, J. 1994a. Inheritance of resistance to pathotypes QCC and MCC of Puccinia graminis f. sp. tritici in barley line Q21861 and temperature effects on the expression of resistance. Phytopathology 84:452-455.

Jin, Y., Steffenson, B. J., and Fetch, T. G. 1994b. Sources of resistance to pathotype QCC of Puccinia graminis f. sp. tritici in barley. Crop Sci. 34:285-288.

Komatsuda, T., Pourkheirandish, M., He, C., Azhaguvel, P., Kanamori, H., Perovic, D., Stein, N., Graner, A., Wicker, T., and Tagiri, A. 2007. Sixrowed barley originated from a mutation in a homeodomain-leucine zipper I-class homeobox gene. Proc. Natl. Acad. Sci. USA 104:1424-1429.

Line, R. F. 2002. Stripe rust of wheat and barley in North America: A retrospective historical review. Annu. Rev. Phytopathol. 40:75-118.

Lipka, A. E., Gore, M. A., Magallanes-Lundback, M., Mesberg, A., Lin, H., Tiede, T., Chen, C., Buell, C. R., Buckler, E. S., and Rocheford, T. 2013. Genome-wide association study and pathway-level analysis of tocochromanol levels in maize grain. G3 (Bethesda) 3:1287-1299.

Lipka, A. E., Kandianis, C. B., Hudson, M. E., Yu, J., Drnevich, J., Bradbury, P. J., and Gore, M. A. 2015. From association to prediction: Statistical methods for the dissection and selection of complex traits in plants. Curr. Opin. Plant Biol. 24:110-118.

Long, A. D., and Langley, C. H. 1999. The power of association studies to detect the contribution of candidate genetic loci to variation in complex traits. Genome Res. 9:720-731.

Mamo, B. E., Smith, K. P., Brueggeman, R. S., and Steffenson, B. J. 2015. Genetic characterization of resistance to wheat stem rust race TTKSK in landrace and wild barley accessions identifies the rpg4/Rpg5 locus. Phytopathology 105:99-109.

Mascher, M., Gundlach, H., Himmelbach, A., Beier, S., Twardziok, S. O., Wicker, T., Radchuk, V., Dockter, C., Hedley, P. E., and Russell, J. 2017. A chromosome conformation capture ordered sequence of the barley genome. Nature 544:427-433.

Meints, B., Cuesta-Marcos, A., Fisk, S., Ross, A., and Hayes, P. 2016. Food barley quality improvement and germplasm utilization. Pages 41-73 in: Exploration, Identification and Utilization of Barley Germplasm. Z. Guoping and L. Chengdao, eds. Elsevier, London, United Kingdom.

Miller, J. D., and Lambert, J. 1955. Variability and inheritance of reaction of barley to race 15B of stem rust 1. Agron. J. 47:373-377.

Mohan, M., Nair, S., Bhagwat, A., Krishna, T., Yano, M., Bhatia, C., and Sasaki, T. 1997. Genome mapping, molecular markers and marker-assisted selection in crop plants. Mol. Breed. 3:87-103.

Moscou, M. J., Lauter, N., Steffenson, B., and Wise, R. P. 2011. Quantitative and qualitative stem rust resistance factors in barley are associated with transcriptional suppression of defense regulons. PLoS Genet. 7:e1002208.

Mukoyi, F., Soko, T., Mulima, E., Mutari, B., Hodson, D., Herselman, L., Visser, B., and Pretorius, Z. 2011. Detection of variants of wheat stem rust race Ug99 (Puccinia graminis f. sp. tritici) in Zimbabwe and Mozambique. Plant Dis. 95:1188.

Muñoz-Amatriaín, M., Cuesta-Marcos, A., Endelman, J. B., Comadran, J., Bonman, J. M., Bockelman, H. E., Chao, S., Russell, J., Waugh, R., and Hayes, P. M. 2014. The USDA barley core collection: Genetic diversity, population structure, and potential for genome-wide association studies. PLoS One 9:e94688.

Muñoz-Amatriaín, M., Moscou, M. J., Bhat, P. R., Svensson, J. T., Bartoš, J., Suchankova, P., Šimková, H., Endo, T. R., Fenton, R. D., and Lonardi, S. 2011. An improved consensus linkage map of barley based on flow-sorted chromosomes and single nucleotide polymorphism markers. Plant Genome 4:238-249.

Myles, S., Peiffer, J., Brown, P. J., Ersoz, E. S., Zhang, Z., Costich, D. E., and Buckler, E. S. 2009. Association mapping: Critical considerations shift from genotyping to experimental design. Plant Cell 21:2194-2202. 
Nazari, K., Mafi, M., Yahyaoui, A., Singh, R., and Park, R. 2009. Detection of wheat stem rust (Puccinia graminis f. sp. tritici) race TTKSK (Ug99) in Iran. Plant Dis. 93:317.

Peterson, R. F., Campbell, A., and Hannah, A. 1948. A diagrammatic scale for estimating rust intensity on leaves and stems of cereals. Can. J. Res. 26c: 496-500.

Pilet-Nayel, M.-L., Moury, B., Caffier, V., Montarry, J., Kerlan, M.-C., Fournet, S., Durel, C.-E., and Delourme, R. 2017. Quantitative resistance to plant pathogens in pyramiding strategies for durable crop protection. Front. Plant Sci. 8:1838.

Prasad, K., Bhatnagar-Mathur, P., Waliyar, F., and Sharma, K. K. 2013. Overexpression of a chitinase gene in transgenic peanut confers enhanced resistance to major soil borne and foliar fungal pathogens. J. Plant Biochem. Biotechnol. 22:222-233.

Pretorius, Z., Bender, C., Visser, B., and Terefe, T. 2010. First report of a Puccinia graminis f. sp. tritici race virulent to the $S r 24$ and $S r 31$ wheat stem rust resistance genes in South Africa. Plant Dis. 94:784.

Pretorius, Z., Singh, R., Wagoire, W., and Payne, T. 2000. Detection of virulence to wheat stem rust resistance gene Sr31 in Puccinia graminis. f. sp. tritici in Uganda. Plant Dis. 84:203.

Pretorius, Z., Szabo, L., Boshoff, W., Herselman, L., and Visser, B. 2012. First report of a new TTKSF race of wheat stem rust (Puccinia graminis $\mathrm{f}$. $\mathrm{sp}$. tritici) in South Africa and Zimbabwe. Plant Dis. 96:590.

Price, A. L., Patterson, N. J., Plenge, R. M., Weinblatt, M. E., Shadick, N. A., and Reich, D. 2006. Principal components analysis corrects for stratification in genome-wide association studies. Nat. Genet. 38:904-909.

R Development Core Team. 2015. R: A Language and Environment for Statistical Computing. R Foundation for Statistical Computing, Vienna, Austria.

Richardson, K. L., Vales, M. I., Kling, J. G., Mundt, C. C., and Hayes, P. M. 2006. Pyramiding and dissecting disease resistance QTL to barley stripe rust. Theor. Appl. Genet. 113:485-495.

Roelfs, A. 1985. Wheat and rye stem rust. Pages 3-37 in: The Cereal Rusts, Vol. 2. A. Roelfs and W. Bushnell, eds. Academic Press, Sydney, Australia.

Rossi, C., Cuesta-Marcos, A., Vales, I., Gomez-Pando, L., Orjeda, G., Wise, R., Sato, K., Hori, K., Capettini, F., and Vivar, H. 2006. Mapping multiple disease resistance genes using a barley mapping population evaluated in Peru, Mexico, and the USA. Mol. Breed. 18:355-366.

Sallam, A. H., Tyagi, P., Brown-Guedira, G., Muehlbauer, G. J., Hulse, A., and Steffenson, B. J. 2017. Genome-wide association mapping of stem rust resistance in Hordeum vulgare subsp. spontaneum. G3 (Bethesda) 7: 3491-3507.

Sato, K., Inukai, T., and Hayes, P. M. 2001. QTL analysis of resistance to the rice blast pathogen in barley (Hordeum vulgare). Theor. Appl. Genet. 102: 916-920.

Sessa, G., and Martin, G. B. 2000. Signal recognition and transduction mediated by the tomato Pto kinase: A paradigm of innate immunity in plants. Microbes Infect. 2:1591-1597.

Sharma Poudel, R., Alhashel, A., Gross, T., Gross, P., and Brueggeman, R. S. 2018. Pyramiding Rpg4 and Rpg1-mediated stem rust resistance in barley requires the Rrrl gene for both to function. Front. Plant Sci. 9:1789.

Shiu, S.-H., and Bleecker, A. B. 2001. Plant receptor-like kinase gene family: Diversity, function, and signaling. Sci. STKE 2001:re22.

Singh, R. P., Hodson, D. P., Huerta-Espino, J., Jin, Y., Njau, P., Wanyera, R., Herrera-Foessel, S. A., and Ward, R. W. 2008. Will stem rust destroy the world's wheat crop? Adv. Agron. 98:271-309.

Singh, R. P., Hodson, D. P., Jin, Y., Huerta-Espino, J., Kinyua, M. G., Wanyera, R., Njau, P., and Ward, R. W. 2006. Current status, likely migration and strategies to mitigate the threat to wheat production from race $\mathrm{Ug} 99$ (TTKS) of stem rust pathogen. CAB Rev. 1:1-13.

Song, W.-Y., Wang, G.-L., Chen, L.-L., Kim, H.-S., Pi, L.-Y., Holsten, T., Gardner, J., Wang, B., Zhai, W.-X., and Zhu, L.-H. 1995. A receptor kinase-like protein encoded by the rice disease resistance gene, Xa21. Science 270:1804-1806.
Stakman, E. C., Steward, D. M., Loegering, W. Q. 1962. Identification of physiologic races of Puccinia graminis var. tritici. U.S. Department of Agriculture Publications E617. USDA, Washington, DC.

Steffenson, B., Case, A., Pretorius, Z., Coetzee, V., Kloppers, F., Zhou, H., Chai, Y., Wanyera, R., Macharia, G., and Bhavani, S. 2017. Vulnerability of barley to African pathotypes of Puccinia graminis f. sp. tritici and sources of resistance. Phytopathology 107:950-962.

Steffenson, B., and Jin, Y. 2006. Resistance to race TTKS of Puccinia graminis f. sp. tritici in barley. Phytopathology 96:S110.

Steffenson, B., Jin, Y., Brueggeman, R., Kleinhofs, A., and Sun, Y. 2009. Resistance to stem rust race TTKSK maps to the rpg4/Rpg5 complex of chromosome 5H of barley. Phytopathology 99:1135-1141.

Steffenson, B., Jin, Y., Rossnagel, B., Rasmussen, J., and Kao, K. 1995. Genetics of multiple disease resistance in a doubled-haploid population of barley. Plant Breed. 114:50-54.

Steffenson, B. J. 1992. Analysis of durable resistance to stem rust in barley. Euphytica 63:153-167.

Steffenson, B. J., and Smith, K. P. 2006. Breeding barley for multiple disease resistance in the Upper Midwest region of the USA. Czech J. Genet. Plant Breed. 42:79-85.

Steffenson, B. J., Zhou, H., Chai, Y., and Grando, S. 2013. Vulnerability of cultivated and wild barley to African stem rust race TTKSK. Pages 243-255 in: Advance in Barley Sciences. Proceedings of the 11th International Barley Genetics Symposium, G. Zhang, C. Li, and X. Liu, eds. Zhejiang University Press, Hangzhou, China.

Sun, Y., and Steffenson, B. 2005. Reaction of barley seedlings with different stem rust resistance genes to Puccinia graminis f. sp. tritici and Puccinia graminis f. sp. secalis. Can. J. Plant Pathol. 27:80-89.

Sun, Y., Steffenson, B. J., and Jin, Y. 1996. Genetics of resistance to Puccinia graminis f. sp. secalis in barley line Q21861. Phytopathology 86:1299-1302.

Taketa, S., Kikuchi, S., Awayama, T., Yamamoto, S., Ichii, M., and Kawasaki, S. 2004. Monophyletic origin of naked barley inferred from molecular analyses of a marker closely linked to the naked caryopsis gene (nud). Theor. Appl. Genet. 108:1236-1242.

USDA-NASS. 2012. United States Department of Agriculture, National Agricultural Statistics Service. Online Publication Quick Stats 2.0. https:// quickstats.nass.usda.gov/

USDA-NASS. 2018. United States Department of Agriculture, National Agricultural Statistics Service. Online Publication Quick Stats 2.0. https:// quickstats.nass.usda.gov/

Wang, M. L., Sukumaran, S., Barkley, N. A., Chen, Z., Chen, C. Y., Guo, B., Pittman, R. N., Stalker, H. T., Holbrook, C. C., and Pederson, G. A. 2011. Population structure and marker-trait association analysis of the US peanut (Arachis hypogaea L.) mini-core collection. Theor. Appl. Genet. 123: 1307-1317.

Wang, X., Richards, J., Gross, T., Druka, A., Kleinhofs, A., Steffenson, B., Acevedo, M., and Brueggeman, R. 2013. The rpg4-mediated resistance to wheat stem rust (Puccinia graminis) in barley (Hordeum vulgare) requires Rpg5, a second NBS-LRR gene, and an actin depolymerization factor. Mol. Plant-Microbe Interact. 26:407-418.

Wolday, A., Fetch, T., Hodson, D., Cao, W., and Briere, S. 2011. First report of Puccinia graminis f. sp. tritici races with virulence to wheat stem rust resistance genes $\mathrm{Sr} 31$ and $\mathrm{Sr} 24$ in Eritrea. Plant Dis. 95:1591.

Xu, J., Xu, X., Tian, L., Wang, G., Zhang, X., Wang, X., and Guo, W. 2016. Discovery and identification of candidate genes from the chitinase gene family for Verticillium dahliae resistance in cotton. Sci. Rep. 6:29022.

Yu, J., Pressoir, G., Briggs, W. H., Bi, I. V., Yamasaki, M., Doebley, J. F., McMullen, M. D., Gaut, B. S., Nielsen, D. M., and Holland, J. B. 2006. A unified mixed-model method for association mapping that accounts for multiple levels of relatedness. Nat. Genet. 38:203-208.

Zhou, H., Steffenson, B., Muehlbauer, G., Wanyera, R., Njau, P., and Ndeda, S. 2014. Association mapping of stem rust race TTKSK resistance in US barley breeding germplasm. Theor. Appl. Genet. 127:1293-1304. 